\title{
0880 RISKY NEIGHBOURHOODS OR STRUCTURAL FLAWS?
}

C Reinprecht, G Datler, C Keckeis, A Kurtev* Correspondence: Centre for Public Health, Liverpool John Moores University, 5th floor Kingsway House, Hatton Garden, Liverpool L3 2AJ, UK

\subsection{6/ip.2010.029215.880}

Since the 1980s, demographic and structural developments have transformed the social dynamics in European cities. Particularly in poorer communities, such changes may increase feelings of insecurity that facilitate social tension and violence. This study investigated several types of change with regard to their impact on local communities, namely: the current generation change in housing estates built in the 1950s and 1960s; spatial planning decisions surrounding new estates and redevelopments; and new forms of migration, such as the influx of new ethnicities. Eight neighbourhoods in Vienna, Austria, were explored using observations and interviewing. In the analysis, a concept of complex insecurity as the intersection of safety and uncertainty was employed to interpret the neighbourhoods' history, built environment, the interplay between social groups, and processes of stigmatisation. Feelings of insecurity were primarily linked to age and ethnicity, and found on all study sites. Certain groups were perceived more often as threatening or unpleasant, especially young persons and recent migrants. The analysis distinguished between perceived and actual causes of latent conflicts. Respondents complained about noise, dirt, lack of adherence to rules and territorial occupancy. In actuality, the study found that environmental factors, such as lack of spaces designated for young people, the generation gap, expressing itself in different lifestyle preferences, as well as the common scepticism between established and outsiders (Elias/Scotson 1965) accounted for the tensions. Practical recommendations for safer communities call for a multifaceted approach, including flexible spaces corresponding with residents' needs and increased local self-administration. 